This is an Open Access article, distributed under the terms of the Creative Commons Attribution licence (http://creativecommons.org/licenses/by/4.o/), which permits unrestricted re-use, distribution, and reproduction in any medium, provided the original work is properly cited.

doi:10.1017/So1 $44686 X_{1} 6000945$

\title{
The meal as a performance: food and meal practices beyond health and nutrition
}

\author{
MARIA NYBERG*, VIKTORIA OLSSON*, GERD ÖRTMAN†, \\ ZADA PAJALIC $\dagger+\$$, HÅKAN S. ANDERSSON†, \\ ANNA BLÜCHER $\uparrow$, ANN-LOUISE LINDBORG\|, \\ KARIN WENDIN* I** and ALBERT WESTERGREN\$
}

\begin{abstract}
The proportion of elderly people in the population is increasing, presenting a number of new challenges in society. The purpose of this qualitative study was to investigate how elderly persons with motoric eating difficulties perceive and perform their food and meal practices in everyday life. By using Goffman's concept of performance as a theoretical framework together with Bourdieu's thinking on habitus, a deeper understanding of food and meal practices is obtained. Semistructured interviews were conducted with 14 elderly people (aged between 67 and 87 years) and meal observations were carried out with 11 of these people. Participants were found to manage food and meal practices by continuously adjusting and adapting to the new conditions arising as a result of eating difficulties. This was displayed by conscious planning of what to eat and when, avoiding certain foods and beverages, using simple eating aids, but also withdrawing socially during the meals. All these adjustments were important in order to be able to demonstrate proper food and meal behaviour, to maintain the façade and to act according to the perceived norms. As well as being a pleasurable event, food and meals were also perceived in terms of being important for maintaining health and as 'fuel'
\end{abstract}

* Food and Meal Science and the Research Group MEAL, School of Learning and Environment, Kristianstad University, Sweden.

$\dagger$ Department of Chemistry and Biomedical Sciences, Linnaeus University, Kalmar, Sweden.

\$ Department of Health, Nutrition and Management, Oslo and Akershus University College of Applied Sciences, Norway.

$\S$ The PRO-CARE Group, School of Health and Society, Kristianstad University, Sweden.

|| School of Innovation, Design and Engineering, Mälardalen University Västerås, Sweden.

I Technical Research Institute of Sweden, Lund, Sweden.

** Department of Food Science, University of Copenhagen, Denmark. 
where the main purpose is to sustain life. This was strongly connected to the social context and the ability to enjoy food and meals with family members and friends, which appeared to be particularly crucial due to the impending risk of failing the meal performance.

$\boldsymbol{K E Y}$ WORDS - elderly people, eating difficulties, food and meal practices, meals, independence, eating aids.

\section{Introduction}

In Europe and in many other parts of the world, the proportion of elderly people $(\geqslant 65$ years) in the population is growing. Between the years 2010 and 2030 it is estimated that the number of Europeans over the age of 65 will rise by almost $4^{0}$ per cent. Many elderly people are living a healthy, active and independent life, and Sweden is one of the countries where self-perceived health scores are highest among European senior citizens (Eurostat 2011). However, others suffer from disabilities and frailty and are in need of extra help in order to manage their everyday activities, such as food purchasing and meal preparation. Some also need assistance in relation to eating. Eating difficulties, defined as 'difficulties that, alone or in combination, negatively interfere with preparation and intake of served food and/or beverages' (Westergren et al. 2001: 258), may be a result of specific diseases, such as Parkinson's disease, stroke or rheumatoid arthritis (Jacobsson et al. 200o), or a consequence of old age itself (Edfors and Westergren 2012). Eating difficulties are complex as they may consist of a variety of problems related to the eating process, including difficulties in the pre-oral phase as well as in managing the food in the mouth and swallowing (Leopold and Kagel 1997). Motoric eating difficulties affect the ability to handle food on the plate as well as to transport the food to the mouth (Jacobsson et al. 2000; Westergren et al. 2009). These difficulties may consist of, for example, tremors, weaknesses in arms, fingers or shoulders, and low handgrip, making it difficult to grasp the cutlery or lift the arm. The problems may also influence the ability to prepare food, set the table, handle and clean the plates and glasses (Gustafsson et al. 2003) and, as a result, may affect total energy and nutrient intakes (McLaren and Dickerson 2000; Wylie, Copeman and Kirk 1999). Eating difficulties are described as an important risk factor for malnutrition among older people (Ekberg et al. 2002; Maitre et al. 2014; Nyberg et al. 2015).

To an increasing extent, older people are living longer in their own homes, meaning that problems in relation to food and eating, and also to an adequate nutrient intake, may not be noticed. Social isolation and 
feelings of loneliness may also increase with old age, especially for those living alone, and the associated health risks are particularly severe for older people (Coyle and Dugan 2012). At the same time, research has frequently indicated the importance of being independent in relation to the practices of everyday life in general, and to food and meals in particular (Berg, Sarvimäki and Hedelin 20o6; Fjellström 20o9; Gustafsson et al. 2003; Perry and McLaren 2003). Strategies to try to maintain independence have been described, such as simplifying cooking and eating and choosing more cold meals and snacks instead of hot meals (Andersson and Sidenvall 2001; Gustafsson and Sidenvall 2002; Lundkvist et al. 2010; Mattsson Sydner et al. 2007). Eating difficulties may affect food choice behaviour, including the variety of food eaten (Edfors and Westergren 2012; Lorefält et al. 2006; Sidenvall, Fjellström and Ek 1994) as well as the experience of the entire meal situation (Gustafsson et al. 2003; Perry and McLaren 2003). Several studies have also indicated lower quality of life as a result of eating difficulties (Acreman 2009; Jacobsson et al. 2000; Tan and Fearon 2008). Eating difficulties, in combination with the endeavour to maintain independence, may result in nutritional problems, including the risk of becoming malnourished (Nyberg et al. 2015).

\section{To stage a meal-the concept of performance}

Eating difficulties may lead not only to reduced and inadequate food and nutrient intake, but also to social withdrawal (Gustafsson et al. 2003) as a result of feelings of shame and guilt at not being able to eat 'properly' (Carlsson, Ehrenberg and Ehnfors 2004; Elsner 2002; Fjellström 2009; Jacobsson et al. 200o; Medin et al. 2010). The inability to eat according to current cultural norms is a sign of 'outsider status' according to Robin Fox (2016). 'Eating properly' includes the type of food that is consumed and how it is eaten, as well as how the food is prepared and served (Fox 2016). A meal taken with others might be seen as a performance taking place on stage and in front of an audience, to use some of sociologist Erving Goffman's metaphors for interactions and social life (Goffman 1959, 1990). As a result of difficulties handling the food on the plate or transporting the food to the mouth, eating becomes not only a struggle to consume sufficient energy and nutrients, but also a conscious act, something that has to be performed, where a certain behaviour has to be staged in every eating situation.

In order to display proper food and meal behaviour, knowledge of certain codes is needed as well as the ability to act according to these codes and cultural norms. Following Norbert Elias's theory of the civilising process (Elias 200o), Sidenvall (1999), in her study of elderly persons in institutions, 
argues that for most people in the Western world using a knife and fork is part of acting in a civilised and proper way at the table. Using fingers when eating, however, has been associated with improper food behaviour (Sidenvall 1999).

\section{The (un-)conscious act of eating - the concept of habitus}

Much etiquette related to food behaviour is routinised and non-reflective. By using Bourdieu's concept of habitus, defined as an incorporated, automated way of acting and thinking in everyday life (Bourdieu 1977), the unreflective part of the eating process may be recognised. Habitus, with its roots in the concept of practice, has been used in earlier studies investigating food-related work among elderly women where the concept has been seen as 'a system of food-related work abilities established during lifelong performance' (Gustafsson et al. 2003: 238). Furthermore, Sidenvall (1999: $3^{21}$ ) clarified these non-reflective aspects by stating that adults normally 'serve food, eat with a knife and fork, and talk about fitting subjects at the table without reflecting on what to do. The practical way of handling these things is automatically performed'. Habitus plays an inevitable and integral part in our daily life as it guides us in the most varying situations, enabling us to act more or less unreflectively. Sobal and Bisogni (20og) use the term food choice scripts to define the behaviour and knowledge that guide the way people act in a specific situation, resulting in routines which provide a sense of predictability and familiarity. From this perspective, these scripts may work as a result of, yet are also part of, the habitus although they are often defined as more flexible than the habitus itself. Our food and meal practices, defined as all those activities involving eating and drinking as well as cooking and preparing food and meals, are to a large extent routinised, taken for granted, and performed habitually or customarily (Neely, Walton and Stephens 2014; Reckwitz 2002). Warde (2016) argues that the practice of eating, understood as mundane, routine and embodied practical competences, has to be recognised in an analysis of eating. In this sense, habitus may be seen as producing social practices. Warde further points out that much of our eating behaviour has to be understood as habitual and unreflective, rather than a result of conscious choices. As a central part of this perspective, food and meals are viewed both as material and as symbols representing thoughts, feelings and relationships (Punch, McIntosh and Emond 2010). In this way, food and meal practices may be defined as both bodily and also mental and emotional activities. Being able to cook, lay the table, carry plates and glasses, as well as use cutlery when eating, transport food to the mouth, open the mouth, chew and swallow all become parts of this incorporated, unreflective knowledge. 
However, as a result of eating difficulties, the process of eating often has to be sensitised and reflected upon differently, in order to find alternative ways of handling food and meal practices. When suffering from eating difficulties, a new learning process related to eating and drinking might be needed in order to master the meal situation and to achieve sufficient nutrient and energy intakes. In her thesis, Wallin (2015) described how people at the end of life who were experiencing eating disabilities thought about and managed food and eating. Feelings of being different and excluded were expressed, as well as feelings of loss and loneliness at not being able to be part of a shared meal. Escaping the social field, or moving 'off stage' (Andersson and Sidenvall 2001; Goffman 1959, 1990, Westergren et al. 2016), has been described as one example of a strategy used when the established habitus is no longer working (Gustafsson et al. 2003).

In order to understand both the social aspects and the possible impacts on food intake and the meal situation, it seems important to gain a better understanding of how elderly persons with motoric eating difficulties manage their difficulties in everyday life. By using Goffman's concept of performance as a theoretical framework, together with Bourdieu's thinking about habitus as a way of understanding automated performed actions, a deeper understanding of food and meal practices might be obtained in relation to elderly people with motoric eating difficulties.

\section{Purpose}

The purpose of this study is to investigate how elderly people with motoric eating difficulties perceive and perform their food and meal practices in everyday life.

\section{Method and material}

This qualitative study is part of the project 'Food and Eating Aids for Independent Ageing', the main purpose of which is to facilitate and improve the food and meal situation among elderly persons with motoric eating difficulties. As part of the project, a literature overview concerning motoric eating difficulties among elderly people has been published (Nyberg et al. 2015), highlighting the many important aspects to be considered in understanding the food and meal situation, especially in relation to the risk of malnutrition. In the current study, 14 semi-structured interviews were conducted with elderly persons. In addition, meal observations were 
conducted with 11 of these participants who had pronounced eating difficulties in order to gain further understanding of how they perceived and performed their meal situation.

\section{The participants}

The inclusion criteria were people aged $6_{5}$ years and over, living in their own home, either alone or co-habiting, and who exhibited motoric eating difficulties of some kind related to transporting food from the plate to the mouth. The elderly persons were recruited from one of two different regions in the south of Sweden. Seven men and seven women were interviewed (aged between 67 and 87 years) and the majority $(\mathrm{N}=11)$ of the participants had distinct motoric eating difficulties related to transporting the food from the plate to the mouth. Three of them suffered from Parkinson's disease, two had suffered a stroke, and five exhibited tremors and/or weakness in one or both arms but without a specified diagnosis. One woman was unable to use her left arm due to brain damage after a fall. Although one of the main criteria for participation was having motoric eating difficulties, three of the participants did not describe any specific eating difficulties during the actual interview situation. However, since it was noticed that they were in the risk-zone for developing or had already developed minor eating difficulties that they themselves did not acknowledge or preferred not to talk about, these persons were included in the study (see Table 1 ).

About half of the participants used eating aids of some kind, more or less frequently. the eating aids used included a 'sip cup', a straw, cutlery with a thicker shaft and glasses adjusted to enable better grip.

\section{Recruitment of the participants}

A convenience sampling including various strategies was used to recruit participants meeting the criteria for the study. Participants were sought through contact with health and social care managers, pensioners' associations, a support centre for relatives, meeting places for elderly people, patients' associations, Parkinson and stroke clinics at hospitals, nutritionists working in hospitals or in primary care, as well as through the researchers' scientific networks, including contacts with people working with elderly. In addition, a total of 3 oo information letters about the project, including a reply coupon, were distributed with the food service transport to elderly persons receiving a daily food delivery in two cities in the south of Sweden. Those elderly persons who replied were contacted by phone, and details of the project and participation were described. The time and place for the interview and meal observation were also arranged. 
TAB L E 1. Description of the study participants

\begin{tabular}{llccl}
\hline Participant & Gender & Age & Co-habiting & Eating difficulties \\
\hline 1 & Female & 87 & No & Tremors \\
2 & Male & 67 & No & Tremors \\
3 & Female & 68 & No & Tremors \\
4 & Female & 85 & No & Tremors \\
5 & Male & 81 & No & Tremors \\
6 & Female & 83 & No & Weakness gripping \\
7 & Female & 73 & Yes & Weakness gripping \\
8 & Male & 78 & Yes & Left hand unusable \\
9 & Male & 87 & No & Tremors \\
10 & Male & 82 & No & Tremors \\
11 & Male & 72 & Yes & None \\
12 & Female & 78 & No & None \\
13 & Male & 75 & No & None \\
14 & Female & 84 & Yes & Tremors \\
& & & & \\
\hline
\end{tabular}

Note: 1. The participant was married but lived alone while her husband, at the time of the interview and observation, was staying at a special care home.

\section{Data collection}

All interviews and observations were performed by two persons, where one person was responsible for asking questions and leading the interview and the other person was responsible for tape recording and taking notes. During three of the interviews with participants who had severe eating difficulties, the participant's partner also took part, in order to provide support in answering the questions.

An interview guide was used to facilitate the interviews, making sure that all of the main topics were covered. The guide consisted of a number of themes and sub-questions covering different aspects of the food and meal situation. The interview started by asking the participant to describe his or her usual daily meal structure, and the subsequent course of the interview depended on the response to this open-ended question. Different aspects of their food and meal situations, and how the participants perceived and performed their food and meal practices in relation to their eating difficulties, were covered through questions about food choice, nutrition, the meal situation and their experience of using eating aids. The interviews lasted between 60 and 75 minutes, and were tape recorded and transcribed verbatim.

The meal observations were carried out as a complement to the interviews, with the purpose of gaining further understanding of the eating difficulties. The observations took place during a meal, where two researchers ate the meal together with the participant. In most cases the observation took place at the participant's home, however, in three cases the 
observations were made at a restaurant or in the dining room at an assisted living residence. During the observations, notes were taken about the general meal situation including setting, atmosphere and presence of meal companions, as well as sitting position and the meal duration. In addition, cooking practices were observed as well as ways of managing related tasks, such as laying the table and opening packages. Notes were also taken about how food and drink were handled during the meal.

The observations were either conducted on a separate occasion or in direct connection to the interviews. The interviews and observations took place in the homes of the participants between February and June 2014. In one case, the participant was staying at a special care home at the time, which thus became the location for the interview and observation.

\section{Data analysis}

The verbatim transcribed interview material was analysed using conventional (latent and manifest) content analysis in order to highlight both the apparent and the deeper or latent meanings in the text. Both manifest and latent content analysis include an interpretation of the text material, although both vary with regard to interpretation depth and abstraction level (Graneheim and Lundman 2004). This was important in order to uncover factors involved in how elderly people perceive and perform their food and meal practices in everyday life. The text was first read several times in order to gain an overall understanding. On the basis of the first readings, distinctive patterns emerged from the text. Initial thoughts and reflections on the text contents were recorded in the margins and were used during the remaining stages of the analysis. Step by step the material was analysed, whilst keeping the aim of the study in mind. Meaning units were then identified, that is assertions from the contents of the text. Meaning units with similar content were organised into different categories. The meaning units were condensed, that is the sentences were shortened, while preserving the core. Sub-categories were created for sorting the analysed material. At the final stage, the sub-categories were linked together into main categories that were in turn linked to the main theme.

In order to validate the analysis, all co-authors were assigned to read two interviews each and follow the steps of analysis as describe above. The findings were then discussed, opposing findings were highlighted, and the final content, labelling of sub-categories, categories and main theme were reached. The final result was discussed by all the authors and achieved a high level of agreement. After this, the notes from the discussions were processed further. The quotes from the interviews were translated from 
Swedish to English for documentation of the results. The translations were initially made by the first author and then discussed with the co-authors to reach consensus regarding the translations.

The notes taken from the observations were thoroughly read through, discussed and analysed in the same way as the interview material. The material from the observations was mainly used to understand further, enrich and strengthen the findings from the interviews. The observations helped to capture the performative aspects of the meal and facilitated understanding of the eating difficulties, in particular of those participants who did not report having eating difficulties. The findings from the observations, mainly manifest, were integrated into the findings from the interviews.

\section{Ethical considerations}

The participants were informed orally and by a written information letter of the purpose of the study, both before and at the time of the interviews and observations. Participation was voluntary and participants were informed of their right to discontinue their participation at any point. All information was treated confidentially. The study design was given an advisory pronouncement (registration number LU2014/132) by the regional ethical board, and guidelines from The Swedish Research Council (2002) were followed during the research process.

\section{Results}

One main theme emerged: striving to maintain health, pleasure and normality through adjustment of the performance at and around the dining table scene. This theme arose after identifying two central categories during the data analysis: adjusted meals and meals as health, fuel or pleasure. Adjusted meals indicated that food and meals were adjusted, re-adjusted and planned for in order to manage the meal situation. The adjustments were primarily enforced with the purpose of establishing and maintaining a sense of normality in life, but also in order to be independent in relation to food and meals. Meals as health, fuel or pleasure were different ways of describing how meals were perceived in daily life. The perception of food and meals had often been subject to change, and was re-valued and experienced differently, both as a result of eating difficulties and as a result of being elderly and living alone.

The adjusted meals category is divided into and presented under the following five sub-categories: (a) sustaining normality through planning and adjustment, (b) use of eating aids, (c) social withdrawal as a way of adjusting 
to eating difficulties, (d) the partner as a meal actor, and (e) striving for independence.

\section{Sustaining normality through planning and adjustment}

Food and meal practices were adjusted and re-adjusted, as well as planned for, in order to compensate for eating difficulties. The ability to perform a meal according to the culture-specific norms and to follow the etiquettes of perceived 'good behaviour' were highly valued. In order to sustain normality, adjustments were made in relation to the food eaten, the place of the meal as well as the social context. One participant talked about how she planned her participation at family parties in order not to end up in a situation where she did not have anywhere to put a glass if her hands started shaking:

...when I am invited to a family party and they serve champagne first, then I start like this with the glass (she demonstrates the tremors), the first thing I think about when I arrive is where I can put the glass. (Participant 14)

By being proactive and planning for such situations, the performance of normality could be sustained. Eating difficulties may also influence the choice of food and the way food is handled and prepared, so as not to behave inappropriately. This could result in avoiding drinks, but also to preferring a soup with suitable texture instead of having to cut meat into pieces.

Interviewer: Do you spill when you drink?

Participant 2: It depends on the drink, I avoid things that splash, I use straws. I choose, for example, pea soup instead of meatballs and things like that.

Another informant also stated how she had to think about and plan for her eating in a somewhat different way.

Now, because of my disabilities, I have to think about what I eat. It has to be food that is easy to transport and get into the mouth, and it has to be something that I can tolerate (Participant 5 ).

\section{Use of eating aids}

Another way to adapt and adjust to eating difficulties was through the use of eating aids. Knowledge and use of specially designed eating aids were limited among the participants. However, some used simpler eating aids, or came up with their own ideas to manage the meal situation as properly as possible, that is, not spilling or splashing food or drinks. Using both hands while drinking, or using only the spoon or the fork are examples of strategies described for handling the process of eating without 
'misbehaving'. One participant talked about using a special bowl that reduced the risk of spilling when eating soup.

There I have a big bowl which I hold with both my hands and transport to my mouth, which I think is good. You get a good grip. In my earlier days there were those bowls with ears on. I have a bowl like that but it is so old and nice I don't dare to use it. (Participant 5)

Another participant described how she used a special mug in order not to spill.

It is hard to eat with a fork and it is not much better with a spoon either ... the glass is stupid because I can't grab it and I have to use both hands. I have a child's mug (she laughs and shows a 'sip cup'). (Participant 3)

Comparisons to things that children use were also presented solutions for trying to perform a meal without spilling, however, the meal was then not performed in a culturally proper way.

I sometimes think about these bibs that you can put underneath the tablemat here (she demonstrates in front of her husband and laughs conciliatorily) ... and the plates that you can attach almost like you did for the children, so they are in place. (Wife of Participant 11 )

Another participant also acknowledged that not eating with a knife and fork or eating something other than soup with a spoon was improper. During the observation he had to switch to a spoon at the end of the meal in order to eat the last food on the plate. At the same time, he mumbled something about this being bad table manners. During the interview he clarified his dilemma while eating:

I cut the food with the knife and fork and then I eat with the spoon. You know, that hand, and that arm, you know when I have to use both, one of them starts shaking and then it's hopeless again ... Otherwise I always use the fork, but it looks a bit rude because you should follow all the conventions. (Participant 9)

The use of specially designed eating aids to manage the meal situation was not that commonly seen in this study, and some participants stated that they had been given little or no information about what is available on the market. However, the use of strategies that helped them to adjust to their eating difficulties was more common. Examples of adjustments described during the interviews and observations were using just the fork or spoon, even though this was sometimes perceived as improper, using special bowls and drinking through straws.

\section{Social withdrawal as a way of adjusting to the eating difficulties}

Not being able to perform a meal properly and act in what is perceived as a normal way also led to social withdrawal. During one of the observations, 
Participant 5 declared, while having his meal in the dining room at his assisted living residence, that if he had eaten at home he would have used his fingers to facilitate eating. However, this was not perceived as an option when having to eat in the presence of others. All of the participants who suffered from tremors felt more or less uncomfortable eating with unknown people. One of the participants, who at the time of the interview was staying at a nursing home, expressed feelings about eating with others:

I eat in the kitchen, I like that and then I always eat alone. Because of my tremors I don't want to eat with others, I get so stressed then ... soup is terrible ... I may take 20-30 minutes, I'm always the last one to finish when I eat out. The tremors affect me a lot nowadays. (Participant 4 )

Another participant also described how he had avoided eating with others since developing Parkinson's disease some years ago. Earlier, he had enjoyed eating out with friends:

It is terrible saying it but I can't handle a knife and fork, the cutlery, normally, so I'd rather not eat with other people. Sometimes it's totally hopeless, sometimes you can't get it to work, sometimes it goes really well, but then you get nervous and tensed because you don't want to show too much ... I say no thanks to all nice dinners now. I just sit there with a headache, feeling stressed. (Participant 9)

Another participant also described how he enjoyed eating out for lunch, but because of his tremors he stated clearly that he did not want company at the table. However, he enjoyed having coffee with his friends at a café in the afternoon:

The funny thing with my table manner is that I don't like talking when I eat ... When I eat, if I tell you the truth, I don't want company when I have my lunch ... I don't get disturbed by people around me, as long as they don't talk to me ... To sit outside and drink coffee at a café, that's nice I think. That is actually a social life. (Participant 1o)

In this way he tried to have his private sphere at the restaurant table, while still enjoying the other people present. The company of friends was desirable when just having coffee and cake because this did not involve having to perform a meal at the same time.

\section{The partner as a meal actor}

The partner, or a family member, may also play a central role in adjusting and planning for the meal. In one of the interviews, the husband received help from his wife in order to handle a knife and fork, which was explained by his wife:

...but it would be good with what there was before, that was both a knife and fork in one. But you manage with my help ... you have to be able to live as normally as possible. (Wife of Participant 8) 
Another participant talked about the difficulties of not having teeth and of having functional disabilities as a result of her stroke. Her husband helped her with the daily activities including, for example, facilitating her eating by cutting the food in smaller pieces. The wife of another participant, who assisted in the interview, further described how she helped her husband with food and meal practices, including opening packages and cutting the food on the plate:

I cut the meat for you because it's difficult for you and then I'm always careful with the salad, for example rocket salad, which I cut up. Then he can't for example cut the bread and make a sandwich because he can't hold it with his hand. And he has a problem with opening all the packages, and if I haven't opened or have screwed the lid on the milk, he takes water if I'm not nearby. (Wife of Participant 8)

A feeling of normality was also sustained by creating a nice meal environment, including the choice of table setting and creating a pleasurable meal atmosphere. This preparation of the meal setting in order to stage a pleasant meal experience could also be performed by the partner.

A napkin and a lighted candle on the table, nice china and glasses. I try to vary the china and glasses depending on the food. I also recognise which glasses and cutlery work best for him. (Wife of Participant 8)

Setting the table nicely, but also the use of a plate to put the delivered food on, were all ways of trying to establish perceived proper meal behaviour. These could also be viewed as strategies to maintain the meal façade.

\section{Striving for independence}

Sustaining normality and adjusting to new conditions in relation to food and meal practices also implied striving for independence, that is to eat independently, to purchase and to cook food, and to decide what, when and with whom to eat. Some participants also described the use of eating aids in terms of being able to manage by themselves, at least from a future perspective. To be able to eat independently was expressed as an important driving force:

It means half my life I must say, because then I decide at least a bit. (Participant 5 )

As was described earlier, the partner or a family member may also be an important actor in facilitating and strengthening the feeling of independence by giving assistance, for example, with cutting food into smaller pieces. The son of one of the participants cooked and prepared the food for his mother every day:

I cut everything into small pieces in order for her to eat independently. (Son of Participant 6) 
The mother responded during the interview that even though she had to eat with 'the wrong hand', as she described it, it was important for her to be able to eat without assisted feeding:

When I eat I need help with getting the food cut into small pieces. I only use a fork and I eat with the wrong hand ... It means a lot that I can eat independently. (Participant 6)

Cooking, as well as eating, was stated as being symbols of independence. Difficulties with transporting pots and plates to the table became obvious during both the interviews and the observations, and one participant highlighted the need for elderly persons to invest in kitchen utensils that are easy to use, to facilitate independence:

First of all one can make it much easier by changing to new pots and casseroles ... and to a smaller pan. Many pans are too big and heavy ... a hand blender is a must, it's extremely good, because then you can make a soup, use some leftovers, even meat, and then the soup gets even better. (Participant 14)

These testimonies shed light on the far-reaching efforts that the participants and their partners are prepared to make in order to maintain normality, including independence, regarding the food and meal situation. The meal may be of great importance in a changing and somewhat uncertain everyday life as the physical and psychological changes associated with ageing take their toll.

\section{Food and meals as health, fuel or pleasure}

Food and meals were perceived and experienced differently by the participants in the study, and were described in terms of health as well as pleasure. On the other hand, meals were also defined as being only fuel, having lost their meaning and with the main purpose of sustaining life. The value and meaning of meals were clearly dependent on the social relations surrounding the meal.

Many of the participants described how the meaning of food and meals was different now compared to earlier in life. Choosing healthy food could be described as a way of prolonging life and maintaining health and life quality. In this way, food and meals were used in order to improve health:

It [the food] means a lot more to me now, because it is part of prolonging life. I don't think I ever thought about if it was healthy or varied before, then you just ate because you were young, or at least younger. (Participant 10)

It was striking how the participants thought about food and health differently compared to when they were younger. Being healthy was described in 
terms of regularity, which is having breakfast, lunch and dinner, and variation, having a varied diet. However, it was not always possible to maintain a regular meal pattern, as a result of, for example, delayed food delivery, loss of appetite, or medications that resulted in a more irregular food intake. Having a varied diet could sometimes be hard to achieve as a result of eating difficulties, but also as a result of lack of interest and knowledge. The evening dinner was one example where lack of variation was expressed, as were feelings of not being imaginative enough with regard to what to eat:

But now my mornings and my evenings start to be identical, I think that is poor and unimaginative, I should be able to come up with something ... maybe what is different is the kind of yoghurt I use. (Participant 10)

The participant described the lack of variation between breakfast and dinner and the risk of the diet being monotonous and not providing enough nutrients and energy. The evening meal was most often described as a cold dish seldom included in the food delivery service. Moreover, the participants living alone most often stated that the unimaginative evening meal was a problem. There was often an ambition to try to eat in a varied way, which was defined as a healthy diet. However lack of interest, energy, knowledge and imagination were described as impeding factors.

The perception of the meal as being enjoyable or not was to a great extent dependent on the social context of the meal. Those participants who had someone to share their meals with more often described meals in positive terms, such as enjoyable and something to look forward to. Here, food and meals played a central role in giving meaning to life, even though the eating difficulties could complicate the eating process. The meal could be described as the highlight of the day:

You think it's very positive that we sit at the dinner table for a long time. If nothing disturbs us we can sit for $1^{1 / 2}$ to 2 hours, especially at weekends. It's really a highlight. (Wife of Participant 8)

Being able to share a meal and being able to cook together were described as things that gave meaning and pleasure:

It means a lot I think. You do things together ... we always eat together and we look at it as a conversation, it's fun if you can discuss different things. Food plays an important role, the meals. (Participant 11 )

Several participants mentioned how eating took longer nowadays. They described how they often had breakfast later in the morning, which may be a result of their disabilities and that routines in general take longer, but this was also described as a result of having more time: 
Sometimes you ran from one place to another, you were always in a hurry ... and it was stressful. Nowadays, I nearly don't dare to say it, my breakfast, it may take one and a half hours before I'm finished. I read my newspaper and drink tea, you have time to enjoy it. (Participant 9)

The meals were also given a higher value if the food was home-cooked or perceived to be home-cooked, either cooked by themselves or a family member. The son of one participant cooked for her every day, which she enjoyed enormously:

It's the highlight of the day, only positive. I have my own chef [meaning her son who cooks for her every day] ... It's something I look forward to. And if the clock turns 10 past 12 I call him and ask where he is. (Participant 6)

The daughter of another participant with diabetes joined her mother almost every day in the late afternoon to share an evening meal that she had prepared earlier the same day. This was described as being of great importance for how the meal was perceived, but also for the willingness to eat and to maintain a regular meal pattern:

Then when she [the daughter] comes home we eat and we talk about what has happened during the day ... we usually have candles on the table, and we have that in the evening as well. (Participant 12)

The ability to cook and share a meal with another person was described as having great importance for how the meal was experienced. However, the possibility to choose the company was highlighted as important to how the meal was perceived, and also the possibility to decide if company was desirable at all meal occasions. This may be especially crucial when eating difficulties influence the ability to perform proper eating behaviour.

Having to involuntarily eat alone was more often associated with a feeling of meaninglessness, something that eroded the joy in the meal. The act of eating had become a necessity rather than a pleasurable event:

You eat because you have to ... frankly because I have to eat, it's not something I look forward to ... you have to have something in your stomach. (Participant 13)

Since her husband became sick, one of the participants stated that meals had changed their meaning and were no longer something to look forward to.

Interviewer: How do you perceive your meals today?

Participant 3: Not very meaningful since my husband got sick. It is boring to eat alone.

The social aspects of the meals were recurrently mentioned as something that, to a great extent, influenced the experience of meals, as well as the meaning attached to meal events. 


\section{Discussion}

This article highlights some of the challenges that older persons with motoric eating difficulties have to face in everyday life. Eating and drinking were described as activities where new ways of acting and thinking were required, and new strategies had to be established in order to manage the meal situation. Descriptions of eating and drinking needing to be both focused on and concentrated on were recurrent in the study. The meal became a conscious activity (Medin et al. 2010) and required a lot of effort (Sidenvall and Fjellström 1994). When discussing the meal as a performance, the concepts on stage and off stage are central, as well as audience, attributes, losing face and team performance (Goffman 1959, 1990). In addition, in order to capture the often unreflective and assumed aspects of our thinking and acting in everyday life, the concept of habitus can be used (Bourdieu 1977). However, as a result of facing the problems related to eating difficulties, a person's habitus might be challenged and need to be re-defined in order to manage the changed conditions (Sidenvall 1999). By using the concept performance together with a broader understanding of habitus as a theoretical framework for this article, central aspects in relation to food and meal practices in everyday life are highlighted. Understanding the meal as a performance not only emphasises the communicative, conscious and staged aspects of a shared meal, but also its complexity in relation to eating difficulties. However, as is strongly argued by Warde (2016), much of our eating in everyday life represents a routine and a non-reflective way of thinking and acting in relation to food. Importantly, it is how food and meal practices generated by a person's habitus are adjusted and transformed to conscious actions and thoughts, and become something that has to be performed and acted on as a result of the eating difficulties. Here, practices and performances need to be understood in relation to the constant struggle to display proper meal behaviour, not least in social contexts.

Food and meal practices, as well as attitudes to food and meals, alter in life and may change with age but also as a result of specific eating difficulties. Changes in health and shifts in a person's lifecourse can result in changes in food trajectories, defined as a person's feelings, thoughts, strategies and actions related to food choice and food behaviour (Sobal and Bisogni 2009). Eating difficulties may influence food choice (Lundqvist et al. 2010), leading, for example, to preference for food that is easy to prepare and avoidance of specific food items. Meals have been described as being 'less elaborate', including fewer cooked meals, more cold meals and snack-events, both as a result of struggling with eating difficulties and of being involuntarily alone (Edfors and Westergren 2012; Mattsson 
Sydner et al. 2007). This is especially notable with regard to older singleliving men with and without eating difficulties (Hughes, Bennett and Hetherington 2004; Kullberg et al. 2008). In this current study, food and meals were, on the one hand, associated with health and pleasure, something that effort was put into, enjoyed and planned for and, on the other hand, described in terms of being only a necessity. The participants in the study who lived alone, both men and women, more often regarded meals as being necessary to stay alive rather than as pleasurable events. This also highlights the importance of understanding the meanings, as well as the dilemmas, of a shared meal. Losing the joy of eating may also result in reduced food intake, which is in general problematic as many elderly people are in need of extra energy and nutrients, especially protein and vitamin D (Bauer et al. 2013; Lamberg-Allardt et al. 2013).

As a result of eating difficulties, the entire meal situation has to be thought about and handled in a new and adapted way. In the study, adjusted meals were described as the need to plan in order to be able to perform and sustain a perceived normality in relation to food and meals, and to avoid improper behaviour in public. This was also acknowledged by Perry and McLaren (2003) where 'getting back to normal' and 'getting by' were identified as central themes in understanding stroke patients' experiences of eating difficulties. Adjusted food and meal practices were all part of maintaining the façade, which was especially crucial when the meal was taking place on stage (Goffman 1959, 1990), that is in a social context in front of other people. In the current study, this was formulated in terms of a special focus on what to eat and when, and preparing the meal by cutting the food in advance. The partner or a family member could also play a central role in facilitating these adjustments, and being helpful in planning for the food and meal practices in everyday life. Here, the partner may be defined as $a$ meal actor involved in staging the meal as a team performance (Goffman 1959, 1990). However, the adjustment process should be seen as a continuous re-adjustment process, often as a result of new problems and challenges that emerge when the character of the eating difficulties changes. This also demonstrates how a person's habitus might be repeatedly challenged.

Furthermore, the use of eating aids was also expressed as a way of adjusting to the new circumstances and, in some instances, maintaining the façade of trying to display proper food behaviour. Eating aids may, therefore, be defined as valuable attributes contributing to not losing face in front of an audience during a performance (Goffman 1959, 1990) through, for example, spilling or splashing. By using special cutlery, sip cups, straws or plates with high edges, the meal performance could be facilitated. At the same time, however, the use of eating aids displays the fact that eating is not performed according to the norms and that previous eating abilities 
have been lost. In the study, attitudes towards the use of eating aids were divided, as was the knowledge of and perceived need for their use. Instead, individual solutions to managing the meal were often adopted, such as using both hands or a straw while drinking, or cutting up the food and then eating it with a spoon. However, feelings of not being able to perform a meal properly were also expressed in relation to these strategies.

As has been stated in previous studies, feelings of shame and guilt have been associated with not being able to eat 'properly' (Elsner 2002; Gustafsson et al. 2003; Medin et al. 2010, 2011, 2012; Westergren et al. 2016). This in turn may result in social withdrawal and a preference for eating alone or 'off stage' (Goffman 1959, 1990) in order to avoid the scrutinising glances of the audience. In this study, withdrawal from social situations that include food and beverages was also described as a form of adjustment to the condition of not being able to perform a meal properly. Wallin $(2015)$ described how withdrawal by those with eating difficulties was to be understood as self-protection in social situations where they felt obliged to act in a 'normal' way but were unable to do so. Similarly, eating difficulties have also been found to cause social withdrawal and have negative consequences for the emotional wellbeing of persons with Parkinson's disease (Westergren et al. 2016). However, in this study, continuing to eat with others also became a symbol of maintaining the structure and security of everyday life. This also highlights the tensions between the meaningful social context of a shared meal, including striving to maintain a sense of normality, and the risk of 'social failure'.

Adjustments in relation to food and meals were also made in order to try to maintain independence for as long as possible. The importance of independence when becoming older, including the ability to manage food and meal practices, has been highlighted as valuable for self-esteem and wellbeing, and it has been strongly associated with striving to live 'a normal life' (Berg, Sarvimäki and Hedelin 20o6; Dunér and Nordström 2005; Eckel, Schreiber and Provident 2012; Fjellström and Mattsson Sydner 2009). In the current study, being able to cook and eat without assistance, or with assistance solely from a partner and/or family members, were described as symbols of independence. In order to adapt to an altered meal situation, multiple strategies have been described for maintaining independence when disease and frailty have caused eating difficulties (Gustafsson et al. 2003). Importantly, however, independence has to be considered in relation to an endeavour to display a normative eating behaviour and in relation to achieving adequate intakes of energy and nutrients. This sometimes involves conflicting behaviours such as, on the one hand, trying to manage by themselves, and on the other hand, managing food and meal practices without 'misbehaving' according to social and cultural norms. In 
the current study, eating with a spoon or just with a fork was perceived as improper in most cases. However, in order to eat independently this could be a solution, at least when eating alone (Gustafsson et al. 2003; Sidenvall, Nydahl and Fjellström 2001). From this perspective, the ability to choose if and when company is desirable might be crucial for elderly persons with eating difficulties who are struggling to perform proper meal behaviour.

Food is an important aspect of identity, symbolising who you are and where you come from as well as your values and priorities in life (Belasco 2008). Moreover, meals defined in terms of commensality (Sobal and Nelson 2003) and events of social gatherings (Holm 2001) are central to health and wellbeing. The meal has also been referred to as an important activity for establishing a sense of continuity in life (Nimrod and Kleiber 2007). Not being able to perform a meal in the same way as earlier in life may not only result in the risk of malnutrition (Westergren et al. 2001) and lower quality of life (Acreman 2009; Jacobsson et al. 2000), but it also raises important issues related to independence and self-esteem, and the ability to manage everyday practices, including food intake and meal performances. Eating and drinking become part of a re-learning process, which includes new ways of handling and thinking about previously well-known activities. Although Bourdieu's view on the concept of habitus tends to be quite static, the need for re-defining earlier embodied knowledge will be necessary in relation to eating difficulties. This also includes the development of new strategies and changed food choice scripts in order to manage various situations (Sobal and Bisogni 20o9). Moreover, the exclusion of meals, voluntarily or involuntarily, may result in social isolation, a problem that is arising in the Western world (Routasalo et al. 2006) partly as a result of more people living in their own homes in old age. As was also demonstrated in the study, those who are not able to eat 'properly' may decline meal invitations and avoid visiting restaurants and eating with others. This also highlights the wider implications of this study in capturing the various and diverse aspects of old age as well as its challenges. In particular, it provides further understanding of the altered conditions for managing food and meals in everyday life for elderly people suffering from eating difficulties.

As a qualitative study focusing on the deeper understanding of food and meal practices among elderly persons with eating difficulties, the aim was not to generalise to other groups of elderly people or to other people with various types of eating difficulties. Due to the specific group of elderly people studied, i.e. home-living with motoric eating difficulties, there were some major challenges in recruiting participants for the study. This resulted in those who participated having a variety of forms and degrees of eating difficulties and a range of underlying diagnoses. However, it was crucial to be particularly sensitive to aspects of integrity and to the 
vulnerable situation arising from being asked to participate, and later questioned and observed in relation to meals and eating difficulties. A large sample would probably be difficult or even impossible to achieve. Due to these circumstances a deeper knowledge and understanding of food and meal practices is probably attained by close contact with fewer participants.

\section{Conclusions}

This study illustrates how food and meal practices are perceived and performed by continuously adjusting and adapting to the new conditions that arise due to eating difficulties. In order to be able to sustain normality and to display proper food and meal behaviour, conscious planning of what to eat and when, avoidance of certain food and beverages, use of simple eating aids, but also social withdrawal during the meals were found to be important. Food and meals were perceived in terms of being important for maintaining health as well as being a pleasurable event, and as 'fuel' where the main purpose is to sustain life. This was strongly connected to the social context and the ability to enjoy food and meals with family members, which appeared to be particularly crucial due to the impending risk of failing the meal performance.

In future research, further knowledge of food and meal practices among elderly persons with motoric eating difficulties will be needed. There should be a focus on aspects such as food accessibility and food preferences in combination with increased knowledge concerning how the use of eating aids may be understood in relation to perceptions of proper food behaviour and the cultural values of the meal. Future studies should also include a wider consideration of the complex aspects of the shared meal, which require special attention in the study of people struggling with eating difficulties.

\section{Acknowledgements}

We would like to thank all our participants in the study as well as those helping us with recruiting participants for the study. This project was financially supported by the Kamprad Family Foundation for Entrepreneurship, Research \& Charity in Sweden.

\section{Statement of ethical approval}

The study design was given an advisory pronouncement registration number (LU2014/132) by the regional ethical board, and guidelines from the Swedish Research Council (2002) were followed during the research process. 


\section{Statement of author contributions}

The meal as a performance Project and study design were by KW and AW and data collection was by MN, VO,GO, ZP and A-LL. All authors contributed to the overall planning of the project, analysing and interpreting the data, as well as drafting and critically revising the manuscript. MN has had the main responsibility for synthesising the result and for the writing process. The authors declare that there are no conflicts of interest.

\section{References}

Acreman, S. 2009. Nutrition in palliative care. British Journal of Community Nursing, $14,10,427-31$.

Andersson, I. and Sidenvall, B. 2001. Case studies of food shopping, cooking and eating habits in older women with Parkinson's disease. Journal of Advanced Nursing, 35, 1, 69-78.

Bauer, J., Biolo, G., Cederholm, T., Cesari, M., Cruz-Jentoft, A.J., Morley, J. E., Phillips, S., Sieber, C., Stehle, P. and Teta, D. 2013 . Evidence-based recommendations for optimal dietary protein intake in older people: a position paper from the Prot-Age Study Group. Journal of the American Medical Directors Association, 14, 8, $54^{2-}-59$.

Belasco, W. 20o8. Food. The Key Concepts. Berg Publishers, Oxford.

Berg, G., Sarvimäki, A. and Hedelin, B. 2oo6. Hospitalized older peoples' views of health and health promotion. International Journal of Older People Nursing, 1, 1, $25-33$.

Bourdieu, P. 1977. Outline of a Theory of Practice. Cambridge University Press, Cambridge.

Carlsson, E., Ehrenberg, A. and Ehnfors, M. 2004. Stroke and eating difficulties: long term experiences. Journal of Clinical Nursing, 13, 7, 825-34.

Coyle, C. E. and Dugan, E. 2012. Social isolation, loneliness and health among older adults. Journal of Aging and Health, 24, 8, $1346-63$.

Dunér, A. and Nordström, M. 2005. Intentions and strategies among elderly people: coping in everyday life. Journal of Aging Studies, 19, 4, 437-51.

Eckel, E., Schreiber, J. and Provident, I. 2012. Community dwelling elderly women and meal preparation. Physical $\mathcal{E}$ Occupational Therapy in Geriatrics, 3o, 4, 344-6o.

Edfors, E. and Westergren, A. 2012. Home-living elderly people's views on food and meals. Journal of Aging Research, Article ID 761291, 1-9.

Ekberg, O., Hamdy, S., Woisard, V., Wuttge-Hannig, A. and Ortega, P. 2002. Social and psychological burden of dysphagia: its impact on diagnosis and treatment. Dysphagia, 17, 2, 139-46.

Elias, N. 2000. The Civilizing Process: Sociogenetic and Psychogenetic Investigations. WileyBlackwell, Oxford.

Elsner, R. J. F. 2002. Changes in eating behaviour during the aging process. Eating Behaviours, 3, 1, 15-43

Eurostat 2011. Europe in Figures: Eurostat Yearbook 2OII. Office for Official Publications of the European Communities, Luxembourg.

Fjellström, C. 2009. The social significance of older people's meals. In Raats, M. M., de Groot, L. and van Staveren, W. (eds), Food for the Ageing Population. Woodhead Publishing, Cambridge, 95-109.

Fjellström, C. and Mattsson Sydner, Y. 2oog. Måltidens Sociala Betydelse-Ett Äldreperspektiv. Nordisk Nutrition, 2, 10-11. 
Fox, R. 2016. Food and Eating: An Anthropological Perspective. Social Issues Research Centre. Available online at http://www.sirc.org/publik/food_and_eating_3.html [Accessed 29 April 2016].

Goffman, E. 1959. The Presentation of Self in Everyday Life. Bantam Doubleday Dell Publishing, New York.

Goffman, E. 1990. The Presentation of Self in Everyday Life. Penguin, London.

Graneheim, U.H. and Lundman, B. 2004. Qualitative content analysis in nursing research: concepts, procedures and measures to achieve trustworthiness. Nurse Education Today, 24, 2, $105^{-12 .}$

Gustafsson, K., Andersson, I., Andersson, J., Fjellström, C. and Sidenvall, B. 2003. Older women's perceptions of independence versus dependence in foodrelated work. Public Health Nursing, 2o, 3, 237-47.

Gustafsson, K. and Sidenvall, B. 2002. Food-related health perceptions and food habits among older women. Journal of Advanced Nursing, 39, 2, 164-73.

Holm, L. 2001. The social context of eating. In Kjaernes, U. (ed.), Eating Patterns: A Day in the Lives of Nordic People. Sifo Report 7, Statens Institutt for Forbruksforskning, Lysaker, Norway, 159-98.

Hughes, G., Bennett, K. M. and Hetherington, M. M. 2004. Old and alone: barriers to healthy eating in older men living on their own. Appetite, 43, 3, 269-76.

Jacobsson, C., Axelsson, K., Österlind, P. O. and Norberg, A. 2000. How people with stroke and healthy older people experience the eating process. Journal of Clinical Nursing, 9, 2, 255-64.

Kullberg, K., Åberg, A. C., Bjorklund, A., Ekblad, J. and Sidenvall, B. 20o8. Daily eating events among co-living and single-living diseased older men. Journal of Nutrition, Health and Aging, 1 2, 3, 176-82.

Lamberg-Allardt, C., Brustad, M., Meyer, H. E. and Steingrimsdottir, L. 2013. Vitamin D - a systematic literature review for the $5^{\text {th }}$ edition of the Nordic Nutrition Recommendations. Food $\mathcal{E}^{\circ}$ Nutrition Research, 57, 22671, 1-31.

Leopold, N. A. and Kagel, M. C. 1997. Dysphagia - ingestion or deglutition? A proposed paradigm. Dysphagia, 1 2, 4, 202-6.

Lorefält, B., Ganowiak, W., Wissing, U., Granerus, A. and Unosson, M. 2oo6. Food habits and intake of nutrients in elderly patients with Parkinson's disease. Gerontology, 52, 3, 160-8.

Lundkvist, P., Fjellström, C., Sidenvall, B., Lumbers, M. and Raats, M. 2010 . Management of healthy eating in everyday life among senior Europeans. Appetite, 55, 3, 616-22.

Maitre, I., Van Wymelbeke, V., Amand, M. and Vigneau, E. 2014. Food pickiness in the elderly: relationship with dependency and malnutrition. Food Quality and Preference, 32, part B, $145^{-} 5^{1}$.

Mattsson Sydner, Y., Sidenvall, B., Fjellström, C., Raats, M. and Lumbers, M. 2007. Food habits and foodwork: the life course perspective of senior Europeans. Food, Culture and Society, 10, 3, 367-87.

McLaren, S. M. G. and Dickerson, J. W. T. 2000. Measurement of eating disability in an acute stroke population. Clinical Effectiveness in Nursing, 4, 3, 109-20.

Medin, J., Larson, J., von Arbin, M. and Wredling, R. 2010. Elderly persons' experience and management of eating situations 6 months after stroke. Disability and Rehabilitation, 32, 16, 1346-53.

Medin, J., Windahl, J., von Arbin, M., Tham, K. and Wredling, R. 2011 . Eating difficulties among stroke patients in the acute state: a descriptive, cross-sectional, comparative study. Journal of Clinical Nursing, 2o, 17/18, 2563-72.

Medin, J., Windahl, J., von Arbin, M., Tham, K. and Wredling, R. 2012 . Eating difficulties among patients 3 months after stroke in relation to the acute phase. Journal of Advanced Nursing, 68, 3, 58o-9. 
Neely, E., Walton, M. and Stephens, C. 2014. Young people's food practices and social relationships. a thematic synthesis. Appetite, $\mathbf{8 2}, 5^{\mathrm{o}-60}$.

Nimrod, G. and Kleiber, D. A. 2007. Reconsidering change and continuity in later life: toward an innovation theory of successful aging. International Journal of Aging and Human Development, 65, 1, 1-22.

Nyberg, M., Olsson, V., Pajalic, P., Örtman, G., Andersson, H.S., Blücher, A., Wendin, K. and Westergren, A. 2015. Eating difficulties, nutrition, meal preferences and experiences among elderly - a literature overview from a Scandinavian context. Journal of Food Research, 4, 1, 22-37.

Perry, L. and McLaren, S. 2003. Coping and adaptation at six months after stroke: experiences with eating disabilities. International Journal of Nursing Studies, 4o, 2, $185-95$.

Punch, S., McIntosh, I. and Emond, R. 2010. Children's food practices in families and institutions. Children's Geographies, 8, 3, 227-32.

Reckwitz, A. 2002. Toward a theory of social practices: a development in culturalist theorizing. European Journal of Social Theory, 5, 2, 243-63.

Routasalo, P. E., Savikko, N., Tilvis, R. S., Strandberg, T. E. and Pitkälä, K. H. 2006. Social contacts and their relationship to loneliness among aged people $-\mathrm{a}$ population-based study. Gerontology, 52, 3, 181-7.

Sidenvall, B. 1999. Meal procedures in institutions for elderly people: a theoretical interpretation. Journal of Advanced Nursing, 3o, 2, 319-28.

Sidenvall, B. and Fjellström, C. 1994. The meal situation in geriatric care - intentions and experiences. Journal of Advanced Nursing, 20, 4, 61 $3^{-2} 1$.

Sidenvall, B., Fjellström, C. and Ek, A. C. 1994. Cultural conceptions of daily planning of meals in geriatric care. Vård $i$ Norden, 14, 2/3, $11-15$.

Sidenvall, B., Nydahl, M. and Fjellström, C. 2001. Managing food shopping and cooking: the experiences of older Swedish women. Ageing E' Society, 2 1, 2, $15^{1-68 .}$

Sobal, J. and Bisogni, C. A. 20o9. Constructing food choice decisions. The Society of Behavioral Medicine, 38, 1, 37-46.

Sobal, J. and Nelson, M. K. 2003. Commensal eating patterns: a community study. Appetite, 41, 2, 181-90.

Tan, B. H. and Fearon, K. C. 2008. Cachexia: prevalence and impact in medicine. Current Opinion in Clinical Nutrition $\mathcal{E}$ Metabolic Care, 11, 4, 400-7.

The Swedish Research Council 2002. Forskningsetiska Principer Inom HumanistiskSamhällsvetenskaplig Forskning [Research Ethics in Social Sciences]. Available online at http://www.codex.vr.se/texts/HSFR.pdf [Accessed 23 April 2016].

Wallin, V. 2015 . Mat och måltider vid livets slut: patienter och närståendes erfarenheter av ätsvårigheter. Licentiate thesis, Karolinska Institutet, Stockholm.

Warde, A. 2016. The Practice of Eating. Polity Press, Cambridge.

Westergren, A., Hagell, P., Wendin, K. and Sjödahl Hammarlund, C. 2016. Conceptual relationships between the ICF and experiences of mealtimes and related tasks among persons with Parkinson's disease. Nordic Journal of Nursing Research, o, o, 1-8.

Westergren, A., Karlsson, S., Andersson, P., Ohlsson, O. and Hallberg, I. R. 200 1. Eating difficulties, need for assisted eating, nutritional status and pressure ulcers in patients admitted for stroke rehabilitation. Journal of Clinical Nursing, 10, 2, 257-69.

Westergren, A., Lindholm, C., Mattsson, A. and Ulander, K. 20o9. Minimal eating observation form: reliability and validity. Journal of Nutrition, Health and Aging, 13, 1, 6-1 1.

Wylie, C., Copeman, J. and Kirk, S. F. L. 1999. Health and social factors affecting food choice and nutritional intake of elderly with restricted mobility. Journal of Human Nutrition and Dietetics, 1 2, 5, 375-80. 
Address for correspondence:

Maria Nyberg, Food and Meal Science,

School of Learning and Environment,

Kristianstad University,

SE-291 88 Kristianstad, Sweden

E-mail: maria.nyberg@hkr.se 